\title{
Two-Thirds of Seniors Like Using a Wellness App
}

Authors: John M. Robinson MD, PhD (1), Gabriel Gorski, MA (2), Suzanne Pugh (3)

(1) Center for Health Informatics, Wellzesta Health Research Institute, Durham, NC, 27701, USA

(2) Ignus Digital, Rio de Janeiro 20241-180, Brazil

(3) Aldersgate Methodist Retirement Community, Charlotte, NC, 28215, USA

Corresponding author: John M. Robinson MD, PhD, Director, Wellzesta Health Research Institute, 201 W Main St, Durham, NC 27701, USA. john.robinson@whri.us (864) 214-5207

\section{Abstract}

Objective: Health/wellness applications on mobile devices (Apps) may positively affect the health of seniors (persons age 65+). But for an App to promote health in its target audience, it must achieve meaningful use. Method: For one and a half years, residents at a Life Plan Community (mean age 86) used a wellness App running on iPad. In a digital survey, residents rated their overall satisfaction with the App on a scale from 1 (strongly dislike) to 10 (strongly enjoy). Results: User satisfaction (96 respondents of 252; 38\% response rate) was distributed with maximum 8, median 7, mean 6.6, and standard deviation 2.3. Discussion: The results suggest that it is feasible to inspire seniors to pursue whole-person wellness using an App: technology may promote "active aging."

\section{Keywords}

Telehealth, mHealth, wellness, preventative medicine 


\section{Introduction}

The number of seniors (persons age 65+) in 2030 is expected to be twice as large as it was in 2000, increasing from 35 million to 72 million persons and representing $20 \%$ of the total U.S. population (Nicole Blair Johnson, Locola D. Hayes, Kathryn Brown, Elizabeth C. Hoo, \& Ethier, 2014). This demographic shift, combined with a higher life expectancy than was the norm in previous decades, is expected to have a substantial effect on U.S. public health, social services, and healthcare systems (CDC, 2013). Furthermore, because many chronic conditions affect seniors disproportionately, associated healthcare costs and use of services also are expected to increase. Medicare spending is expected to nearly double in the next decade as a result of growth in this population and increased healthcare costs (Neuman \& Cubanski, 2017). Mobile health/wellness technology may promote preventive health in seniors to partially offset the projected cost increases (Wicklund, 2017).

Life Plan Communities, formerly called Continuing Care Retirement Communities (Zebolsky, 2014), provide a comprehensive solution for active aging by offering the $4 \mathrm{H}$ 's: healthcare, hospitality, housing, and holistic wellness. Seniors enter the community as residents in independent living, then advance to assisted living and skilled care as needed. Life Plan Communities, which number more than 2000 in the U.S. (Katie Sloan, Daniel J. Hermann, Lisa McCracken, 2017), are ideally suited to deploy telehealth technology (Chamberlain, 2016) for seniors.

Today's senior population, particularly the Baby Boomer generation, are tech savvy and have high expectations, technologically speaking, of the communities that they are considering for their future. Nearly $75 \%$ of internet users age $65+$ say they go online daily (Anderson \& Perrin, 2017). $67 \%$ of Americans age $65+$ now get news on a mobile device (Lu, 2017). Yet pitfalls to successful technology adoption are many: limited access to WiFi, availability of mobile devices, mobile device usability issues, App usability issues. Addressing these pitfalls is a prerequisite for using technology to promote population health of seniors. Here, we investigate whether these pitfalls can be successfully addressed in a community setting. 


\section{Methods}

Wellzesta Life, a wellness App, was deployed to residents in independent living ("residents") at Aldersgate United Methodist Retirement Community in Charlotte, NC (CAST, 2017). Aldersgate is a CARF-accredited Life Plan Community. Each resident was given an iPad that contained the App. All residents received basic instruction on using the iPad and using the App. As a security measure, all residents were asked to check-in daily using the App.

At 18 months post-deployment, we conducted a user satisfaction survey. A four question survey was constructed using Google Forms (Figure S1). An announcement was posted in the Wellzesta Life V2 App for 5 days. The announcement invited users to complete the online survey that was accessed via hyperlink within the App. Question 1 solicited preferences related to the selection of calendar dates. Question 2 solicited preferences regarding how events should be displayed (cardview vs. listview). Question 3 solicited user satisfaction with a previous version of Wellzesta Life (V1). Question 4 solicited user satisfaction with the current version of Wellzesta Life (V2). The combined use of URL obfuscation (standard in Google Forms) and URL shortening minimized the chance that uninvited persons could access the survey. User responses were automatically recorded in a Google spreadsheet. Summary statistics and plots were available in the response tab of the survey. Responses to question 4 were further analyzed in the Google spreadsheet.

Descriptive statistics were calculated using native functions available in Google spreadsheets.

\section{Results}

The study population was comprised of 252 residents at a Life Plan Community that actively use Wellzesta Life. Of the 281 residents who are licensed to use the App, 252 (90\% of 281 licensed users) are active users--those who checked-in at least once during the 5 day survey period. Table 1 summarizes demographics of the population. The population had a mean age of 86 , were $64 \%$ female, and predominantly (>95\%) caucasian. The population is broadly representative of residents in independent living at the more than 2000 Life Plan Communities across the United States. 
Table 1. Segmentation of the study population by age and gender.

$\begin{array}{lr}\text { Group } & \text { Number (\%) } \\ \text { All Ages } & 252(100 \%) \\ \text { Female } & 159(63.1 \%) \\ \text { Male } & 93(36.9 \%) \\ \text { Ages 62-69 } & 5(2 \%) \\ \text { Female } & 3(60.0 \%) \\ \text { Male } & 2(40.0 \%) \\ \text { Ages 70-79 } & 45(18 \%) \\ \text { Female } & 31(68.9 \%) \\ \text { Male } & 14(31.1 \%) \\ \text { Ages } 80-89 & 153(61 \%) \\ \text { Female } & 93(60.8 \%) \\ \text { Male } & 60(39.2 \%) \\ \text { Ages } 90+ & 49(19 \%) \\ \text { Female } & 32(65.3 \%) \\ \text { Male } & 17(34.7 \%)\end{array}$

Residents responded to an in-App solicitation (Figure 1) to complete an online survey (Figure S1). 96 persons completed the survey ( $38 \%$ response rate). Residents rated their overall satisfaction with the App on a scale from 1 (strongly dislike) to 10 (strongly enjoy). Responses were asymmetrically distributed with maximum 8, median 7, mean 6.6, and standard deviation 2.3 (Figure 2). 


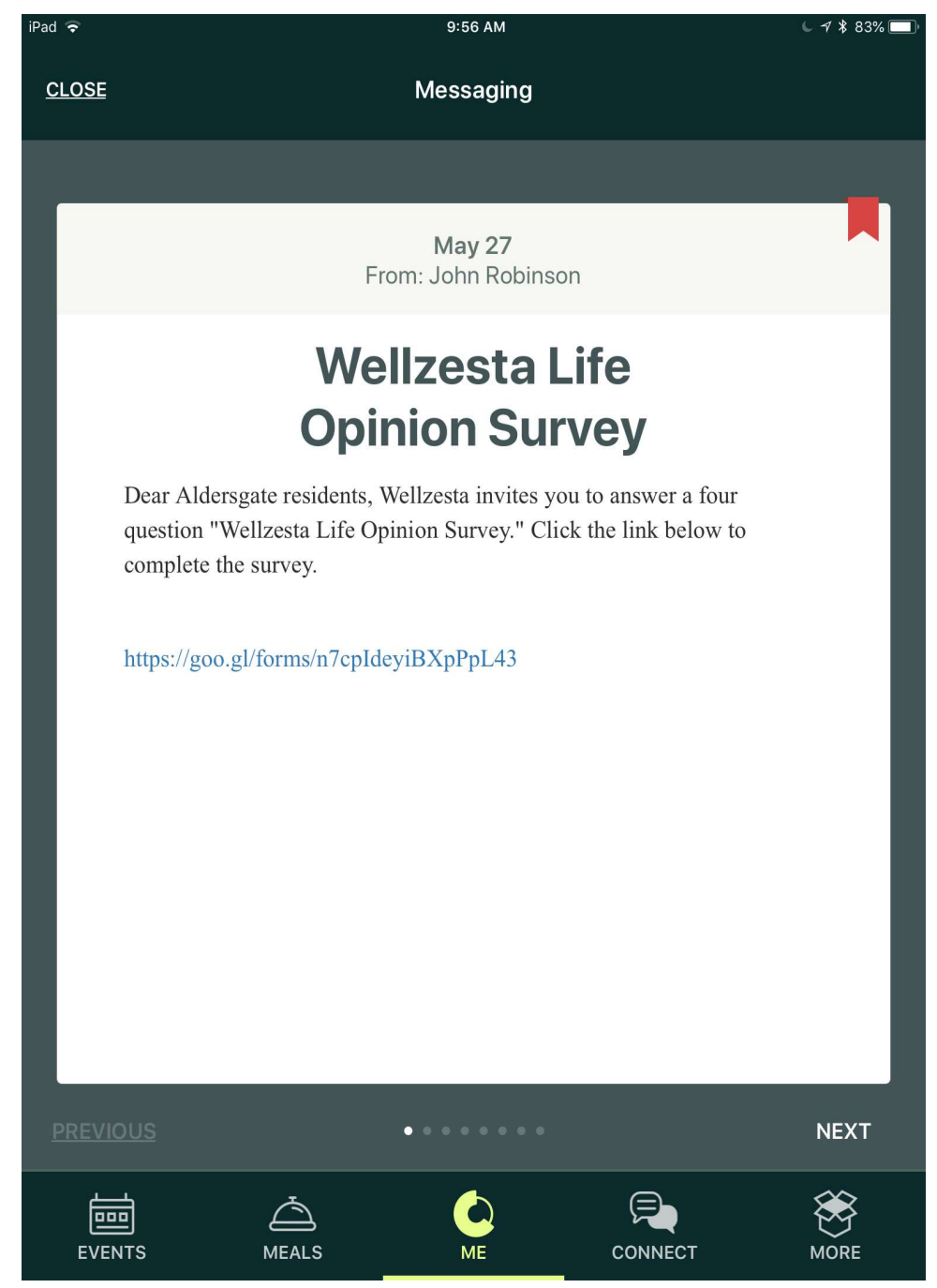

Figure 1. In-App announcement soliciting participation in the survey.

\section{What is your experience with Wellzesta Life version 2?}

\section{6 responses}

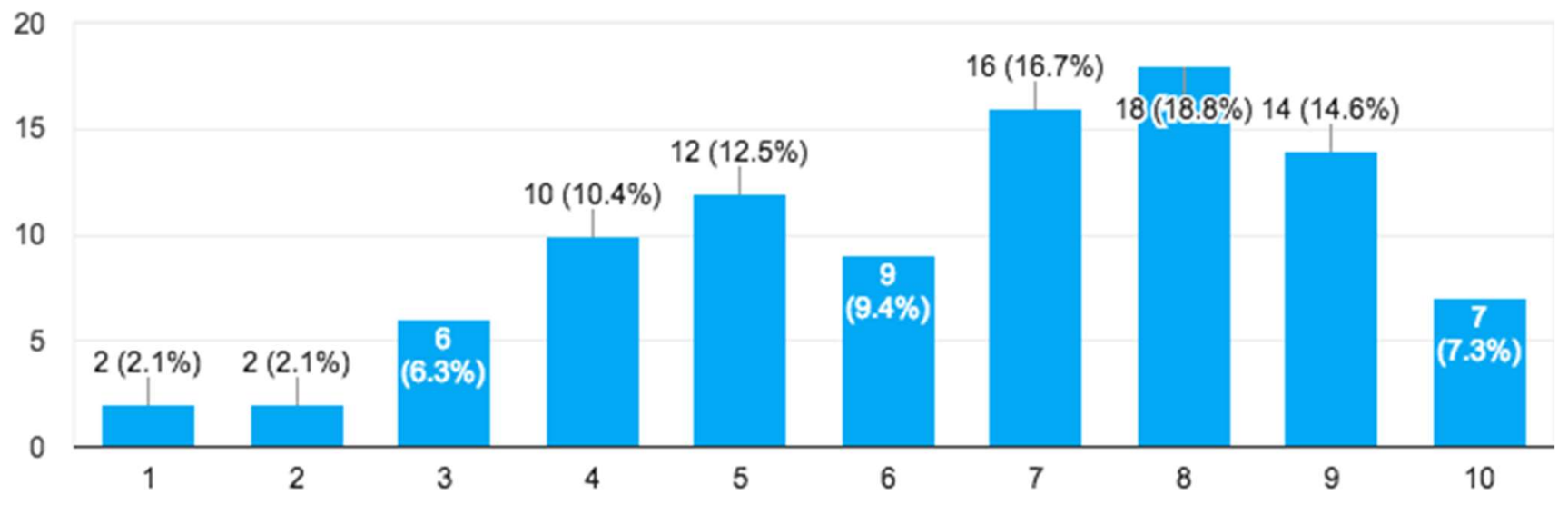

Figure 2. Histogram showing technology satisfaction responses ranging from 1 (strongly dislike) to 10 (strongly enjoy). 


\section{Discussion}

Many senior living communities and technology providers are increasingly in conversation about how new software, devices, and platforms can create a better resident experience and increase resident engagement. Marketing directors at Life Plan Communities report that more than 50\% of prospective residents age $62-75$ inquire whether WiFi is available (Sell, 2018). In a 2016 survey, $81 \%$ of senior living communities report making investments in high speed internet connectivity (wired or wireless) during the past 12 months (McCracken, 2017). A 2018 national study found technology adoption for senior living communities is on the rise (Katie Sloan, Daniel J. Hermann, Lisa McCracken, 2017). National organizations like LeadingAge Center for Aging Services (CAST) offer resources, including strategic planning tools, technology selection guides, case studies, and support for senior living organizations who want more information on technology. Industry leaders expect technology utilization to increase (Smith, 2018). The user satisfaction results reported here support these efforts.

The survey methods used here were entirely digital. Specifically, the solicitation was communicated digitally, the survey itself was administered digitally, and user responses and their analysis were handled digitally. The survey was self-service, and users users opted-in to take the survey. Most Life Plan Communities administer facilitated paper-based (analog) surveys to measure resident opinion. By "facilitated," we mean that they require staff or a polling agency to administer.

The study did not compare the efficacy of analog vs. digital survey methods. However, we would like to identify a few advantages and a disadvantage of the digital approach. The digital self-service strategy offered high user participation (38\%), essentially no added cost, rapid results, and data integrity---results collected automatically in a spreadsheet that could be further processed. More than $50 \%$ of the responses came within 24 hours of the solicitation (data not shown). However, since residents who dislike using mobile technology would be less likely to participate in the survey, it is possible that the results may be biased towards residents who enjoy using technology. Nevertheless, $4 \%$ of the respondents (4 of 96) significantly dislike the App (reported 1 or 2 ). 
This strongly suggests that the digital format of the survey did not hinder participation in the survey from residents who dislike mobile technology.

In the United States, given recent focus on health promotion by health care providers and large employers, the pursuit of wellness is often limited by engagement, not opportunity (Mattke et al., 2015; Meador et al., 2016). Moreover, many are unsure whether technology can, and will, be used by seniors to promote engagement in health/wellness. Here, we observe that $2 / 3$ of seniors (mean age 86 ) like using a wellness App. Meaningful use of the App is a prerequisite to achieving its broader goal: to "inspire engagement in whole-person wellness." Achieving whole-person wellness should lead to the desired lifestyle outcome of "active aging," which translates into population health. Subsequent studies will examine the ability of the App to achieve its broader goal.

Conflict of interest statement: John Robinson is the Chief Executive Officer of Wellzesta, Inc., creator of the Wellzesta Life platform.

Contributors: JMR was involved in planning, analyzed the data, and prepared drafts and final version of the manuscript. GG prepared images for the survey and edited the final manuscript. SP reviewed the results and edited the final manuscript.

Funding Acknowledgement: This study was supported by a grant support from the Aldersgate United Methodist Retirement Community Foundation, Inc. (to JMR).

Data sharing statement: No additional data are available.

\section{Running Title}

Wellness App

\section{Biographies}

John M. Robinson MD, PhD is Director of the Wellzesta Health Research Institute. 
Suzanne Pugh is CEO of Aldersgate Methodist Retirement Community.

\section{References}

Anderson, M., \& Perrin, A. (2017, May 17). Tech adoption climbs among older adults. Retrieved June 5, 2018, from http://www.pewinternet.org/2017/05/17/tech-adoption-climbs-among-older-adults/

CAST. (2017). Enhancing the Lives of Seniors through Use of a Daily Life Management Platform. Retrieved May 30, 2018, from http://leadingage.org/case-studies/social-connectedness-and-engagementtechnology-case-studies

CDC. (2013). The State of Aging \& Health in America. Retrieved from http://www.cdc.gov/aging/pdf/stateaging-health-in-america-2013.pdf

Chamberlain, G. (2016). Deconstructing the Telehealth Industry. Retrieved June 1, 2018, from https://www.ziegler.com/z-media/3159/zielger_telehealth_whitepaper_final.pdf

Katie Sloan, Daniel J. Hermann, Lisa McCracken. (2017). LeadingAge Ziegler 150. Retrieved from http://eziegler.com/Files/LZ150-2017_FINAL.pdf

Lu, K. (2017, June 12). Growth in mobile news use driven by older adults. Retrieved May 30, 2018, from http://www.pewresearch.org/fact-tank/2017/06/12/growth-in-mobile-news-use-driven-by-older-adults/

Mattke, S., Kapinos, K., Caloyeras, J. P., Taylor, E. A., Batorsky, B., Liu, H., ... Newberry, S. (2015). Workplace Wellness Programs: Services Offered, Participation, and Incentives. Rand Health Q, 5(2), 7.

McCracken, L. (2017). Ziegler CFO Hotline: Technology Spending. Retrieved May 30, 2018, from https://www.ziegler.com/z-media/3289/ziegler-cfo-hotline-report-january-2017-technology-spendingImb.pdf

Meador, A., Lang, J. E., Davis, W. D., Jones-Jack, N. H., Mukhtar, Q., Lu, H., .. Molloy, M. E. (2016). Comparing 2 National Organization-Level Workplace Health Promotion and Improvement Tools, 20132015. Preventing Chronic Disease, 13, E136.

Neuman, J., \& Cubanski, T. (2017, July 18). The Facts on Medicare Spending and Financing. Retrieved June 5, 2018, from https://www.kff.org/medicare/issue-brief/the-facts-on-medicare-spending-and-financing/ 
Nicole Blair Johnson, M., Locola D. Hayes, M., Kathryn Brown, M., Elizabeth C. Hoo, M., \& Ethier, K. A. (2014, October 31). CDC National Health Report: Leading Causes of Morbidity and Mortality and Associated Behavioral Risk and Protective Factors_United States, 2005-2013. Retrieved June 5, 2018, from https://www.cdc.gov/mmwr/preview/mmwrhtml/su6304a2.htm

Sell, H. (2018, June 1). personal communication.

Smith, A. (2018, February 9). 7 Leaders Share Predictions for the Future of Senior Living. Retrieved May 30, 2018, from https://info.seniorlivinginnovationforum.com/blog/7-leaders-share-predictions-for-the-future-ofsenior-living

Wicklund, E. (2017, May 4). mHealth, Telehealth Providers Target Growing Senior Care Market. Retrieved June 5, 2018, from https://mhealthintelligence.com/news/mhealth-telehealth-providers-target-growingsenior-care-market

Zebolsky, G. T. (2014). An introduction to continuing care retirement communities. Retrieved from http://us.milliman.com/insight/2014/An-introduction-to-continuing-care-retirement-communities/ 